\title{
instituto de la Commonwealth
}

ROBERT MATTHEW, JOHNSON-MARSHALL \& PARTNERS, J. D. y A. J. HARRIS, arquitectos e ingenieros

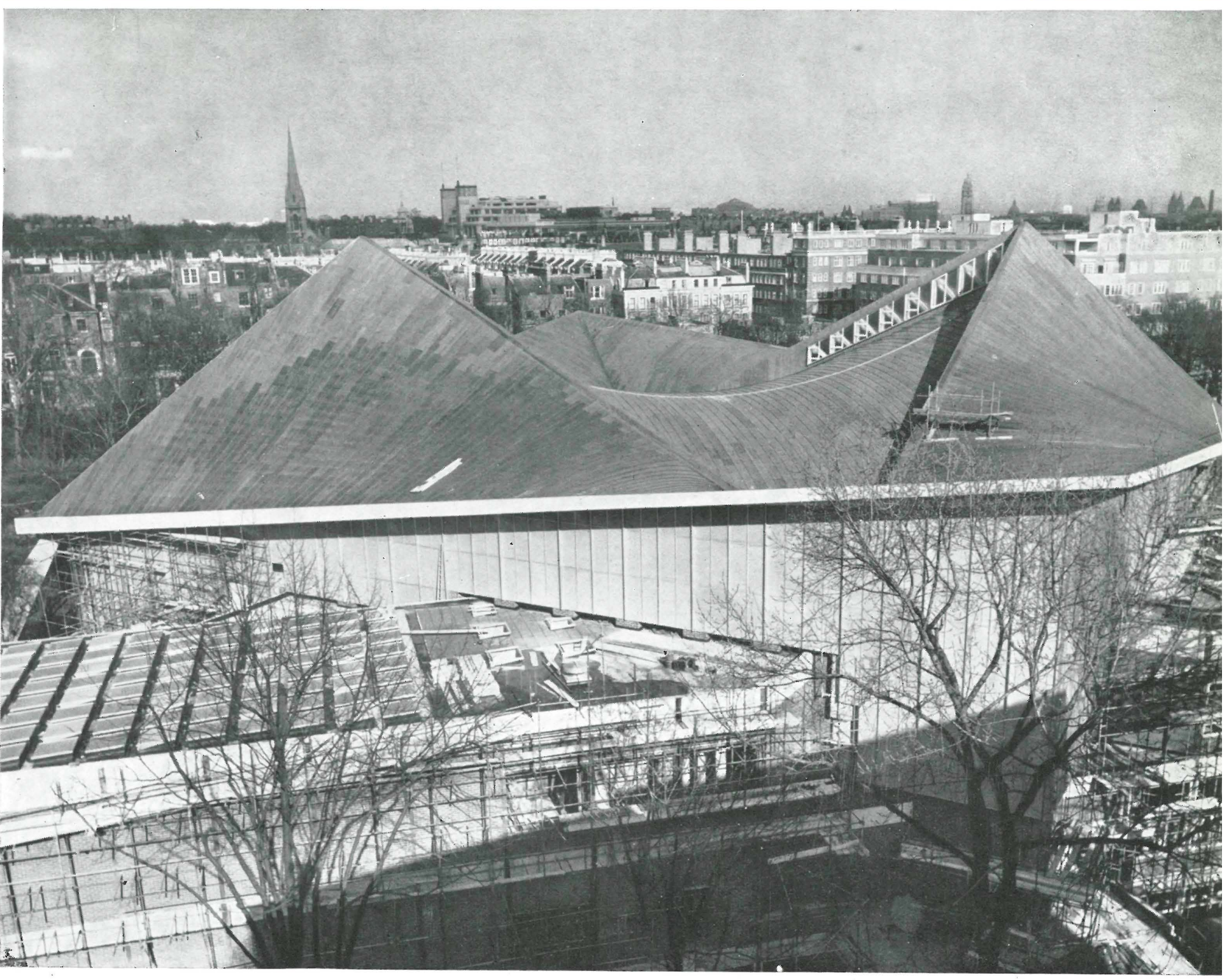

$886 \cdot 3$

Actualmente se está construyendo en Londres (Inglaterra) el edificio para el Instituto Commonwealth. Este Instituto, cuyo objeto es el de abrir una exposición permanente de los distintos países que constituyen la Commonwealth, constará no sólo de dicha exposición, sino de un cuerpo de edificio anexo para la Administración, otro para Museo de pinturas y una sala para cine.

El interés de esta obra se centra en la cubierta del cuerpo edificado para la exposición permanente.

Cimientos.-Aunque de cotas muy variadas en profundidad, en general, los cimientos se apoyan sobre las capas de grava que cubren los bancos arcillosos de la región de Londres.

Tanto los sótanos como otras zonas más superficiales se han construido sin separación alguna por medio de membranas o cortinas aislantes, pero se tuvo especial cuidado en reducir, en la medida de lo posible, el grado de retracción. 


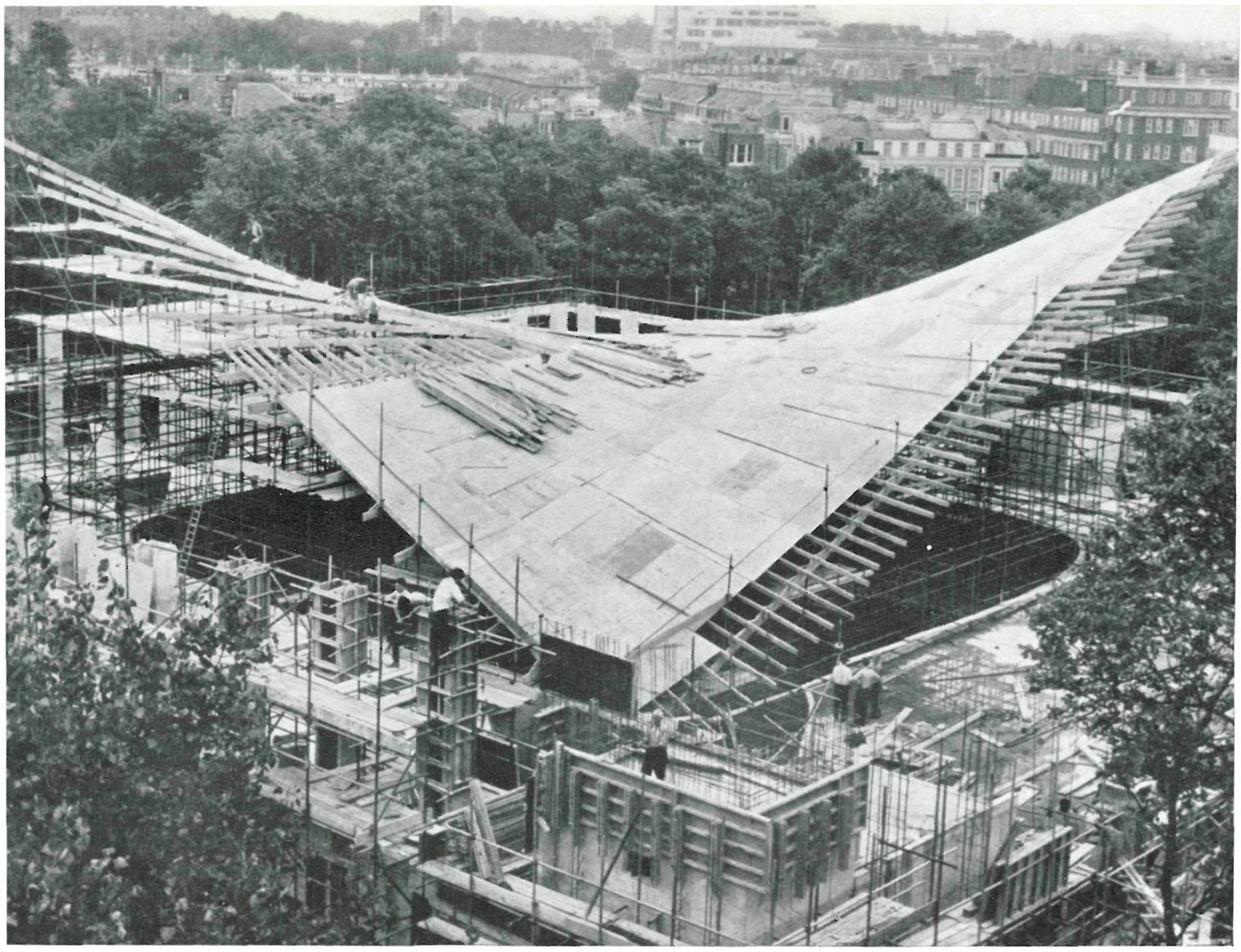

Construnceión

El edificio anexo para la Administración.-Este edificio constituye un cuerpo independiente, de hormigón armado, tipo corriente, capaz de ser ampliado en altura con tres plantas más. Las columnas exteriores, de hormigón negro, decoran el exterior de este edificio.

Museo y Cine.-Estos dos edificios también anexos, tienen una anchura de $12,20 \mathrm{~m}$. El Museo de pintura, totalmente de hormigón armado, está constituido por una estructura con vigas de sección en forma de $\mathrm{T}$ y cubierta con elementos ligeros. El cine
presenta las mismas características generales, salvo que ha sido proyectado para conseguir una luz uniforme.
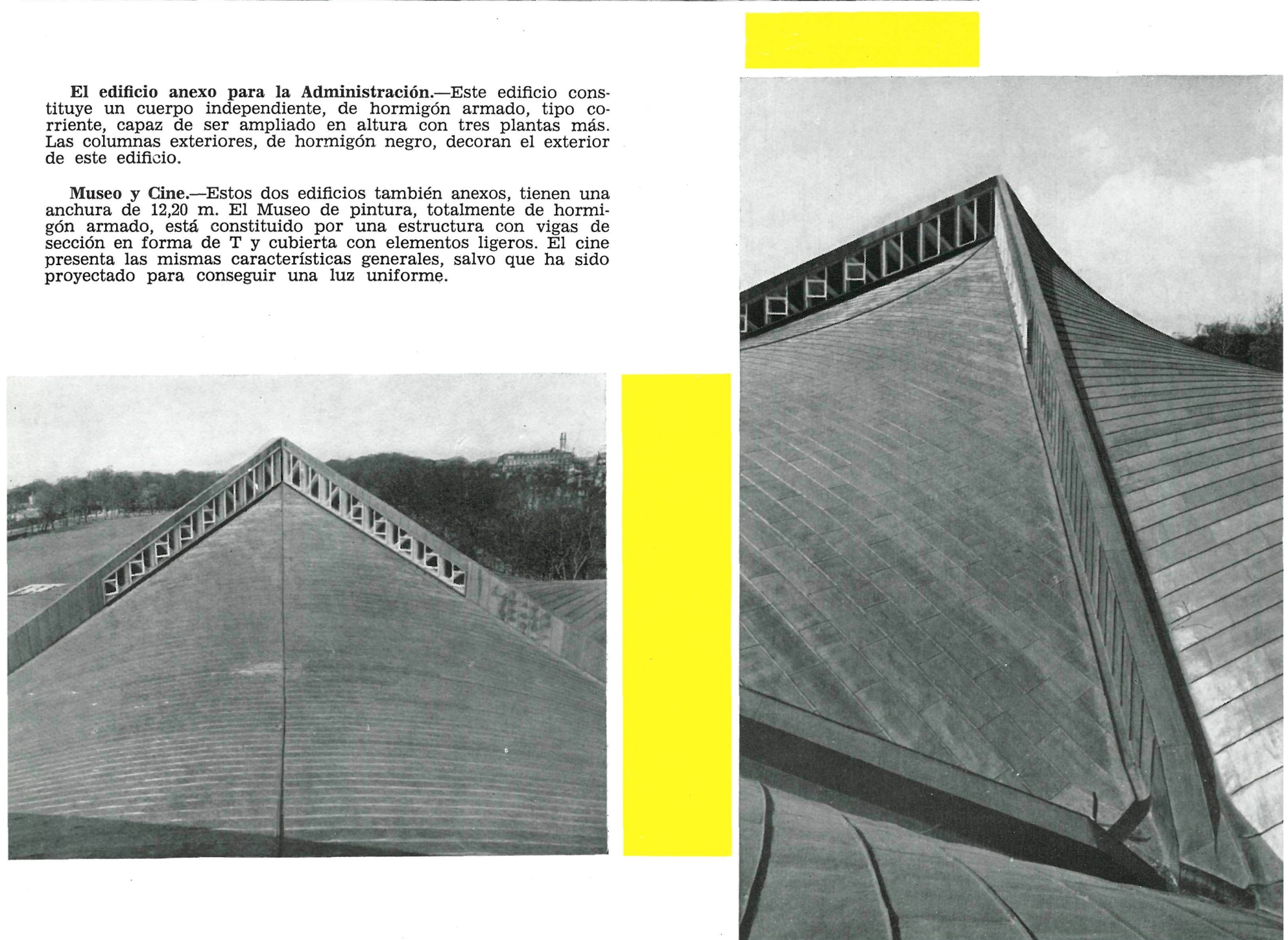


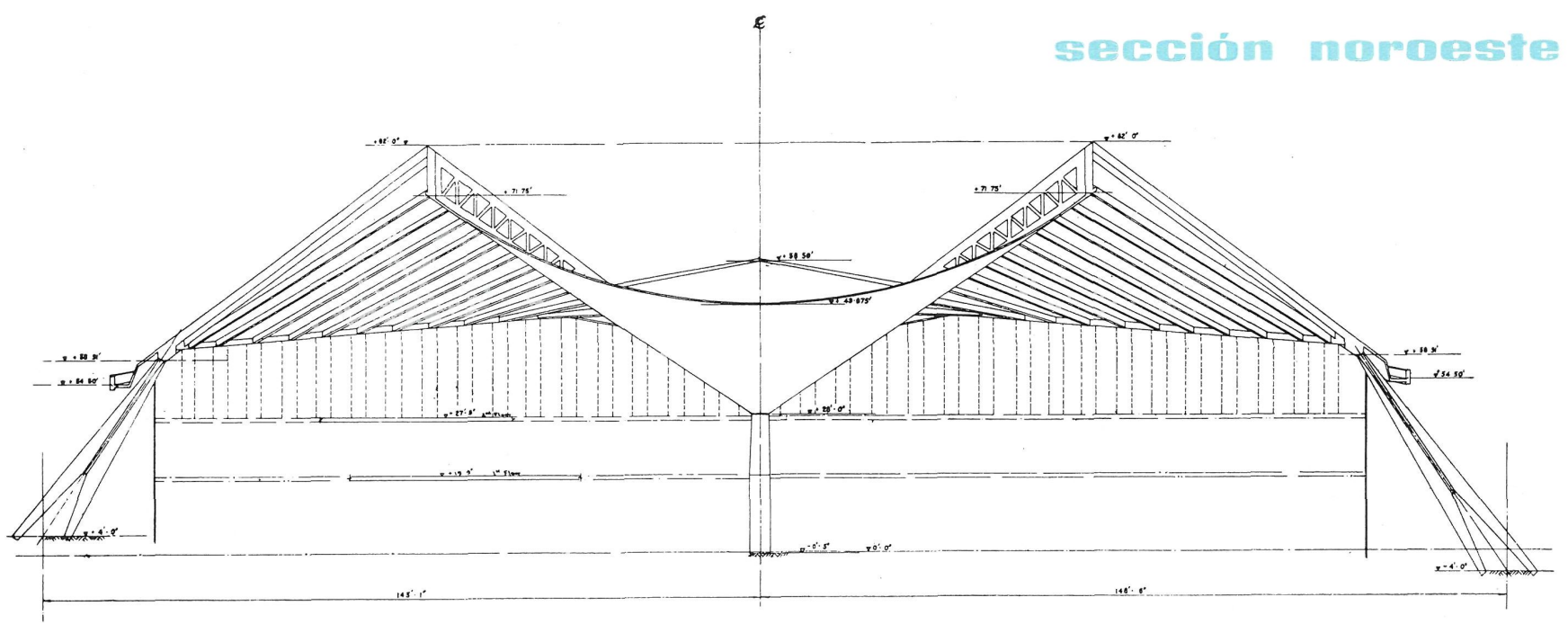

Salón de exposición permanente.-En planta, y aunque a varios niveles, la superficie ocupada por el solado es un cuadrado de $47,20 \mathrm{~m}$ de lado.

Estos solados, a distintos niveles, se unen entre ellos por medio de tramos cortos de escaleras. La diferencia de niveles, combinada con las grandes aberturas que la ventilación exige, constituyen un complicado complejo.

La primera planta se apoya en una serie de soportes dispuestos en forma circular. El forjado vuela al exterior formando ménsula, con lo que se amplía la superficie para formar un cuadrado de $50 \mathrm{~m}$ de lado. Las canalizaciones para la ventilación bordean, en su parte inferior, a la ménsula, y para la descarga se han previsto otras canalizaciones que dan a la segunda planta y a la cubierta.

La segunda planta es similar a la primera, pero dispone de una mayor amplitud en su abertura central. El forjado de esta planta vuela unos $3,60 \mathrm{~m}$ al exterior de los soportes. Los forjados de estas plantas tienen $0,30 \mathrm{~m}$ de espesor. El conjunto, así definido, constituye un todo lejos de un fácil proyecto. En la parte superior de los soportes se han previsto placas, de forma cruciforme, de acero dulce, dedicadas a absorber el esfuerzo cortante.

La cubierta de la exposición permanente.-En planta, la cubierta se proyecta sobre un cuadrado de $59,80 \mathrm{~m}$ de lado, incluyendo la extensión de los aleros. En síntesis, la cubierta se compone de una lámina central, cuadrada en su proyección sobre un plano horizontal, de $28,30 \mathrm{~m}$ de lado, de forma parabólica, flanqueada por otras cuatro superficies también alabeadas. Fn realidad, estas últimas superficies no son hiperbólico-parabólicas, si bien su generación se logra por un par de generatrices rectilíneas, una de ellas desplazándose paralelamente al perímetro, y la otra, moviéndose radialmente apoyándose en el centro del edificio.

Esta superficie compleja condujo a la decisión de emplear una lámina de hormigón para la parte central que acusa una pronunciada curvatura, mientras que para las otras cuatro partes exteriores, también regladas, más planas, se empleó una construcción nervada más ligera.

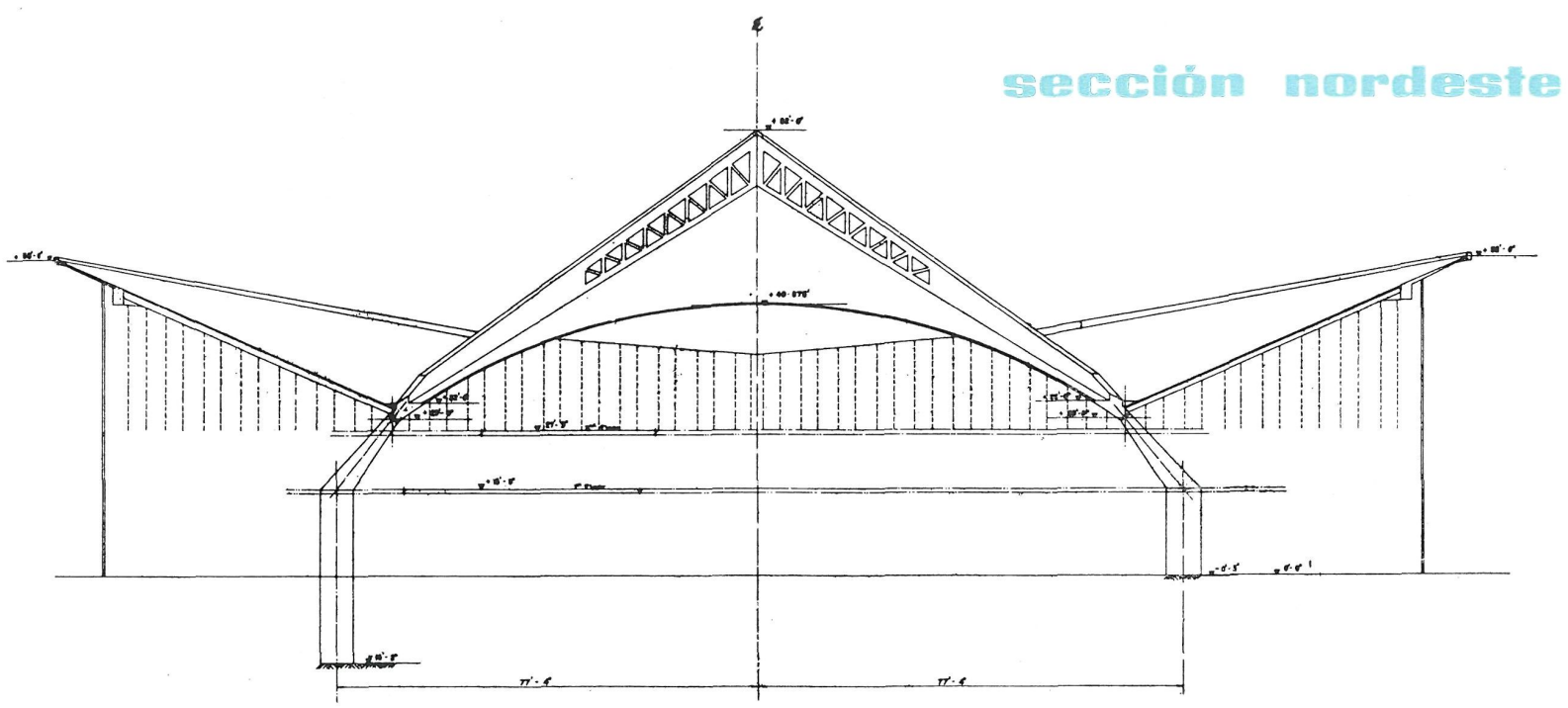




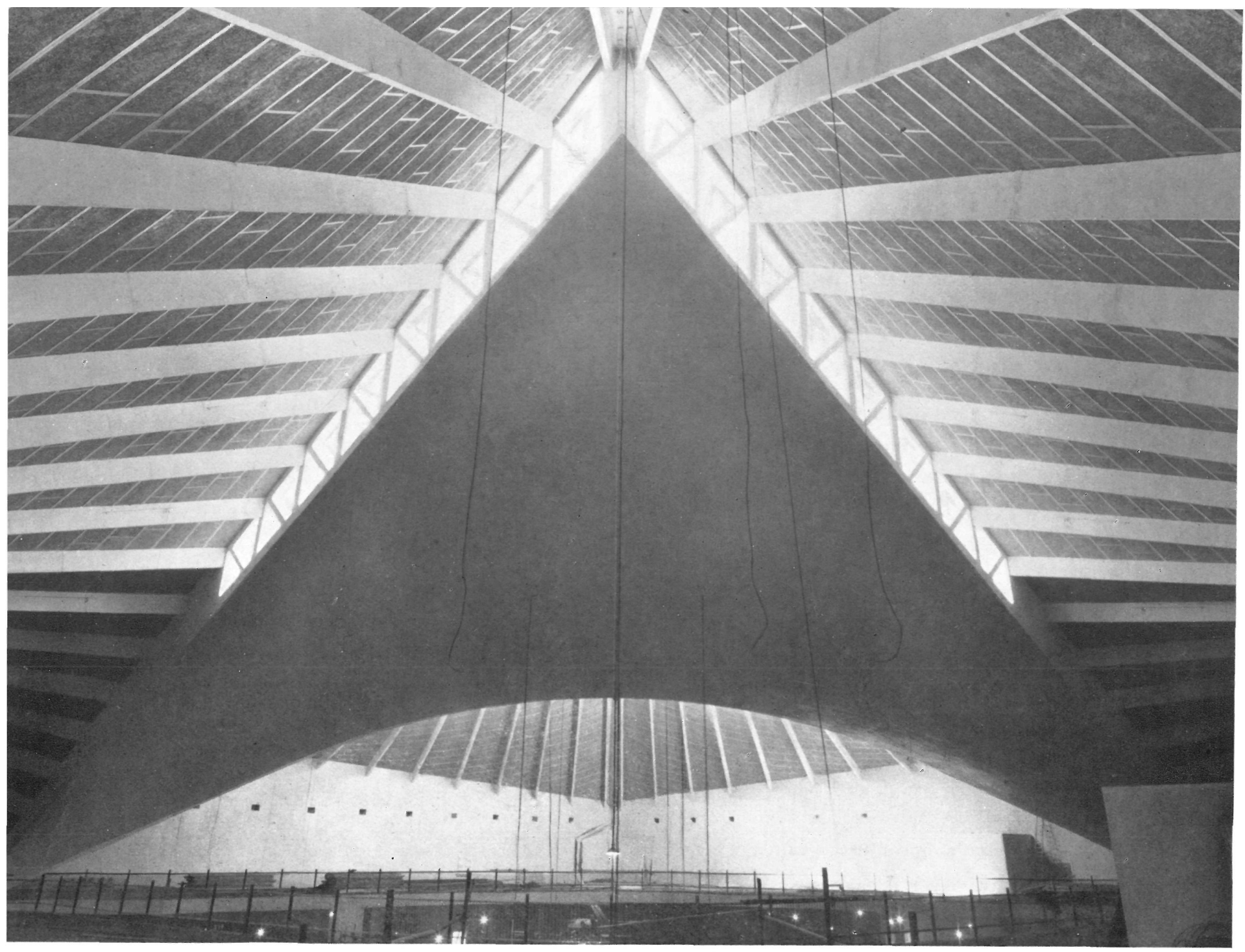

Fotos: JOHN LAING \& SON Ltd.

La lámina parabólica central tiene $7,5 \mathrm{~cm}$ de espesor en su parte central, y $18 \mathrm{~cm}$ en el borde. Esta lámina se ha pretensado en la dirección de las reacciones parabólicas.

En la unión entre la lámına ceniral y los faldones hacia el exterior se han colocado cuatro vigas o nervios triangulados en la parte o extremidad superior para formar lucernarios, mientras que estos nervios son macizos en la otra extremidad más baja. Estos nervios transfieren a los soportes interiores los esfuerzos creados en las láminas, así como los que originan las viguetas que sobre ellos se apoyan y que sostienen los faldones reglados que flanquean a la lámina parabólica central.

Las extremidades superiores de los nervios triangulados se apoyan sobre dos soportes que van al exterior.

La altura desde estos nervios triangulados al nivel del perímetro es de 10,6 m. Como apoyo de las láminas que flanquean a la parte central se han dispuesto una serie de viguetas, que siguen las alineaciones de las generatrices rectilíneas radiales, trabajando como vigas simplemente apoyadas, y que se extienden hasta el apoyo exterior.

Entre las viguetas, y como apoyo del material de cubrición, se han colocado piezas de fibra de madera, con sección en forma de U, debidamente incurvadas para adaptarse a la forma de la superficie. Los aleros son de hormigón circunstancia que se aprovechó para reducir, por su propio peso, la deformación por flexión en las viguetas.

Los drenes que desaguan el agua de lluvia recogida por la cubierta descienden apoyándose en los cuatro soportes principales.

Con objeto de poder rectificar las deformaciones de la cubierta se han previsto, en la parte superior de cada uno de los cuatro soportes principales, gatos planos y un juego de cuñas metálicas que, actuando sobre ellos convenientemente, se podrá recunerar su forma original en caso de deformaciones provocadas accidentalmente. 